\title{
Esophageal obstruction due to a collapsed biodegradable esophageal stent
}

A 74-year-old man with a previous history of surgery for pharyngolaryngeal neoplasia and reconstruction in 2006 with muscle graft was referred to our unit for dysphagia. Upper endoscopy showed a narrow stricture at the muscle graftesophageal anastomosis that was $20 \mathrm{~mm}$ long. The patient underwent five sessions of esophageal dilation with the CRE Balloon Dilator (Boston Scientific, Natick, Massachusetts, USA) with early relapse and weight loss.

Therapeutic options were discussed with the patient, and we decided to place an 80-mm SX-ELLA Esophageal Degradable BD stent (ELLA-CS, Hradec Králové, Czech Republic). It was placed under fluoroscopic guidance without complications. The patient presented an initial improvement from dysphagia grade 4 to dysphagia grade 2, but after 9 weeks he attended the emergency ward for aphagia.

An urgent upper endoscopy was performed showing a collapse of the biodegradable stent mesh inside the esophageal lumen ( $\bullet$ Fig. 1); the collapsed mesh did not allow the passage of a standard Pentax endoscope. A foreign body forceps was used to remove the filaments of partially reabsorbed polydioxanone mesh until a clear lumen was obtained that allowed easy passage of the endoscope ( $\bullet$ Fig. 2). The patient was discharged from hospital the next day with an improvement of his dysphagia.

Endoscopy_UCTN_Code_CPL_1AH_2AD

\section{Competing interests: None}

\section{O. Nogales Rincon, A. Huerta Madrigal, B. Merino Rodriguez, C. Gonzalez} Asanza, E. Cos Arregui, P. Menchen Fernandez-Pacheco

Department of Gastroenterology, Hospital General Universitario Gregorio Marañon, Madrid, Spain

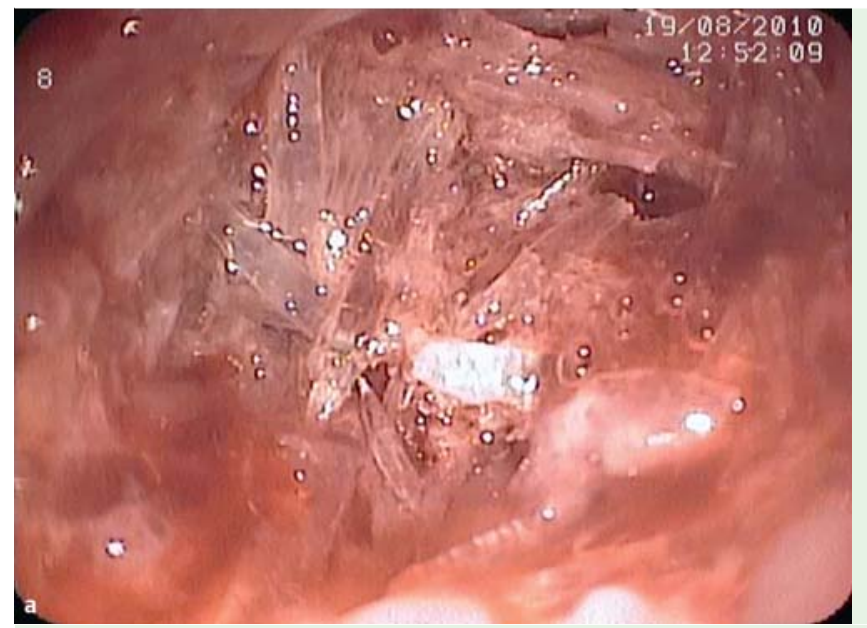

Fig. 1 a-c Biodegradable stent mesh collapsed inside the esophageal lumen.

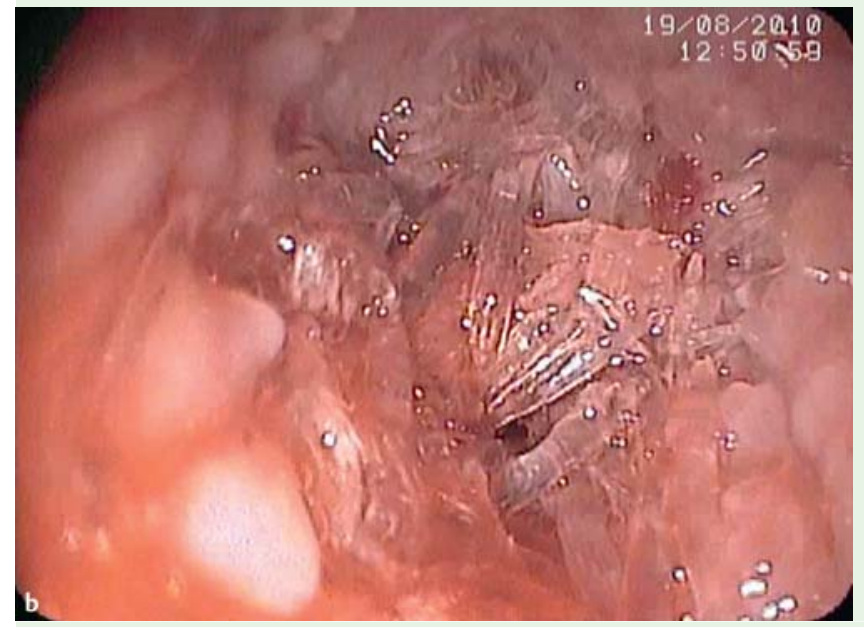




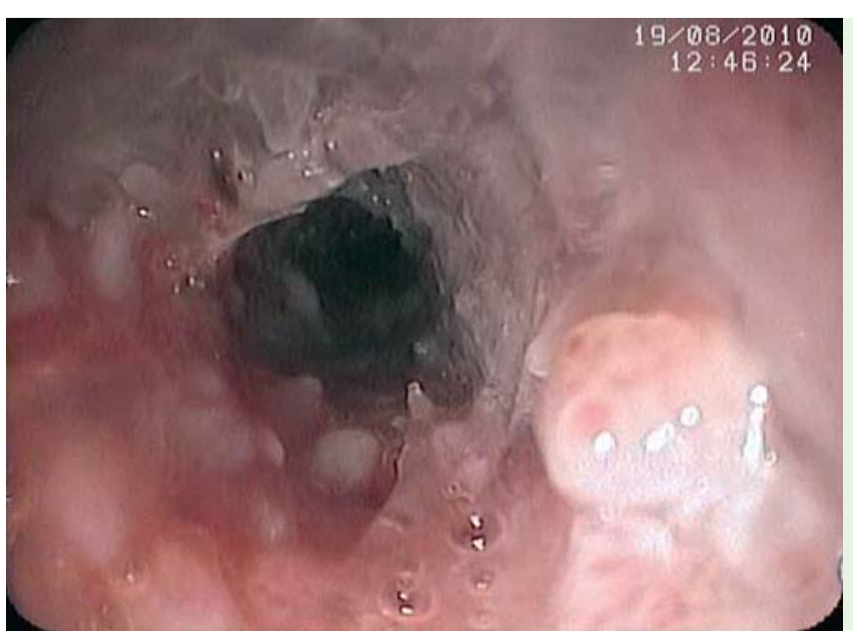

Fig. 2 Esophageal lumen after removing the stent mesh with foreign body forceps.

\section{Bibliography}

DOI $10.1055 / \mathrm{s}-0030-1256324$

Endoscopy 2011; 43: E189-E190

(c) Georg Thieme Verlag KG Stuttgart · New York . ISSN 0013-726X

\section{Corresponding author}

\section{O. Nogales Rincon MD}

Department of Gastroenterology Hospital General Universitario Gregorio Marañon Calle del Doctor Esquerdo, 46 28006 Madrid

Spain

Fax: +34-91-5868307

oscarnogalesrincon@gmail.com 